\title{
CONTRIBUIÇÕES DO PIBID À FORMAÇÃO INICIAL DE PROFESSORES NA COMPREENSÃO DE LICENCIANDOS BOLSISTAS
}

\author{
PIBID CONTRIBUTIONS TO INITIAL TEACHER TRAINING IN THE \\ UNDERSTANDING OF UNDERGRADUATE SCHOLARSHIP STUDENTS
}

RAUSCH, Rita Buzzi

ritabuzzirausch@gmail.com

Universidade Regional de Blumenau - FURB

FRANTZ, Matheus Jurgen

matheus@musicarte.com.br

Universidade Regional de Blumenau - FURB

\begin{abstract}
RESUMO O Programa Institucional de Bolsa de Iniciação à Docência - PIBID prevê bolsas para estudantes de licenciatura que, sob orientação de professores universitários e sob supervisão de professores experientes da Educação Básica, realizam propostas de intervenção docente nas escolas. A Universidade Regional de Blumenau - FURB participa deste programa desde 2010 e atualmente quase todos os cursos de licenciatura da universidade possuem subprojetos vinculados ao PIBID. Diante desta trajetória de dois anos de participação, o objetivo desta pesquisa foi compreender as contribuições do PIBID à formação inicial de professores nos dizeres dos licenciandos pibidianos da FURB. Participaram da pesquisa $60 \%$ dos acadêmicos integrantes dos diferentes subprojetos existentes. A coleta de dados foi realizada por meio de memoriais em que procedemos análise qualitativa de conteúdo. As principais contribuições à formação inicial de professores manifestadas pelos licenciandos foram: a relação entre Universidade e a Educação Básica; o desenvolvimento profissional docente; a valorização profissional docente; o desenvolvimento da reflexividade docente; a formação do professor pesquisador; a qualificação do ensino; a formação do professor leitor; o desenvolvimento de novas metodologias de ensino e o trabalho colaborativo. A relevância do estudo se dá pela recente implantação do Programa no Brasil, incentivando sua manutenção e ampliação, bem como a criação de novas propostas que envolvam todos os alunos de licenciatura e que valorizem a profissão docente no país.
\end{abstract}

PALAVRAS-CHAVE: Formação Inicial de professores. Docência. Educação Básica.

ABSTRACT The Institutional Scholarship Program for Teaching Initiation (PIBID, in Brazil) provides scholarships for undergraduate students who, under the guidance of 
professors and under the supervision of experienced teachers of basic education, conduct teaching intervention proposals in schools. Blumenau's Regional University (FURB) has been awarded with this program since 2010 and currently almost all teaching courses of the University have subprojects linked to PIBID. Given this twoyear working path, this research is aimed at understanding the contributions of PIBID to the initial training of teachers through FURB undergraduates' words. $60 \%$ of the academic members of the different existing subprojects participated in this survey. Data collection was conducted through memorials which underwent qualitative analysis. The main contributions raised by the undergraduates were: the relationship between the University and Basic Education; teacher's professional development; teacher's professional valorization; development of teacher's reflection; education for the teacher-researcher; teaching qualification; education for the teacher-reader; development of new teaching methods and collaborative work. The relevance of this study is given by the recent implementation of the Program in Brazil, encouraging its maintenance and expansion, as well as the creation of new proposals involving all undergraduate students and that value the teaching profession in the country.

KEYWORDS: Teaching. Initial teachers training. Basic Education.

\section{INTRODUÇÃO}

As exigências contemporâneas à docência, juntamente com o baixo prestígio que esta profissão enfrenta e, consequentemente, a perda de status social demonstrado pela sua baixa procura, interferem na escolha pela profissão docente. Conforme nos alertam Gatti e Barreto (2009), salários e planos de carreira pouco atraentes interferem nas escolhas profissionais dos jovens e na representação e valorização social da profissão de professor. No que se refere especialmente à formação inicial de professores, tais autoras destacam que atualmente enfrentamos vários problemas, dentre eles a falta de conhecimento dos contextos escolares; a pouca formação pedagógica dos professores formadores; o não acompanhamento da prática pedagógica dos licenciandos, que sentem dificuldade de relacionar teoria e prática no cotidiano escolar.

Este falta de aproximação entre a formação inicial de professores com o cotidiano escolar, muitas vezes, impossibilita os licenciandos de compreender as relações humanas que se constroem na dinâmica interativa e peculiar de cada instituição, movidas pelos processos de aprender e de ensinar, elementos essenciais ao papel da escola. Este distanciamento, muitas vezes, impossibilita também de os licenciandos perceberem que: 


\begin{abstract}
Escola é lugar de aprender. E de ensinar. É também lugar de tomar merenda, de jogar futebol, de fazer fila, de ficar triste ou se alegrar. As crianças escrevem, somam ou subtraem, copiam, perguntam. Elas brigam, choram, se machucam. Fazem grandes amigos. O professor explica a lição, lê histórias, pega na mão da criança que começa a escrever. Ele também grita, fica bravo, perde a calma. Tem que fazer chamada, corrigir prova, preparar aula, preencher papelada. As crianças às vezes têm fome, às vezes estão doentes, às vezes estão sadias e felizes. De onde elas vêm? Do bairro ao lado, da favela ali em cima, do outro lado da avenida, do sítio a alguns quilômetros. Falta lápis e, por vezes, até o sapato. Trinta (ou quarenta?) em cada sala. Lousa nova, lousa gasta. Carteiras meio quebradas. O diretor se preocupa com a reforma do prédio, orienta e fiscaliza os professores, tem um monte de papel para assinar, é homenageado na formatura. $\mathrm{Na}$ escola tem mais gente: merendeira, servente, secretário, inspetor... O salário está baixo. A vida está dura. Mas escola é lugar de ensinar e de aprender (FONTANA; CRUZ, 1997, p.3).
\end{abstract}

Tentando amenizar tal distanciamento e valorizar a profissão docente o Ministério da Educação está implantando novos programas que contribuem com a qualidade da formação inicial de professores. O PIBID - Programa Institucional de Bolsas de Iniciação à Docência foi criado em 2007 e é coordenado pela Diretoria de Educação Básica Presencial (DEB) da Coordenação de Aperfeiçoamento de Pessoal de Nível Superior (CAPES). Têm como objetivos principais: integrar Educação Superior e Educação Básica; qualificar a formação inicial de professores; fomentar práticas docentes e experiências metodológicas de caráter inovador e tornar a escola pública um espaço para reflexão e crescimento na construção do conhecimento. Portanto, seu intuito é minimizar a falta de prestígio da profissão docente e a desarticulação entre a teoria e a prática escolar, estimulando o acesso e a permanência de estudantes em cursos de licenciatura. O programa prevê bolsas para estudantes de licenciatura que, orientados por um professor de universidades conveniadas e um professor experiente da Educação Básica, realizem projetos com o intuito de aproximar a teoria das licenciaturas à prática de salas de aula da rede pública de ensino (BRASIL, 2012).

Com este Programa busca-se estimular a integração da Educação Superior com a Educação Básica, estabelecendo projetos de cooperação que melhorem a qualidade do ensino nas escolas da rede pública, elevar a qualidade das ações pedagógicas voltadas à formação inicial de professores nas licenciaturas das instituições de Educação Superior e fomentar práticas docentes e experiências 
metodológicas de caráter inovador, bem como tornar a escola pública espaço de reflexão e crescimento na construção do conhecimento docente.

Os participantes do PIBID são inseridos no cotidiano escolar, planejam e participam de experiências metodológicas, tecnológicas e práticas docentes de caráter inovador e interdisciplinar, buscando superar problemas identificados nos processos de ensinar e de aprender. Com os processos de formação e atuação nas escolas, estudos direcionados aos problemas cotidianos observados, os acadêmicos interagem com situações escolares reais. Provém destas ações a procura de respostas para um melhor desempenho nos processos de ensinar e de aprender.

O exercício de docência permite um processo de reflexão na/sobre/para a prática, a fim de que se possa aprimorá-la, tendo como objetivo principal a aprendizagem do aluno. Conforme Tardif (2007, p. 53):

[...] a prática pode ser vista como um processo de aprendizagem por meio do qual os professores retraduzem sua formação e a adaptam à profissão, eliminando o que Ihes parece inutilmente abstrato ou sem relação com a realidade vivida e conservando o que pode servir-lhes de uma maneira ou de outra.

Nesta integração entre Universidade e Educação Básica, a escola torna-se protagonista nos processos de formação dos licenciandos e os professores experientes tornam-se co-formadores de futuros professores. Portanto, com esse projeto que articula ensino, pesquisa e extensão, envolvendo escola e universidade, existe a possibilidade de trocas e melhorias nos processos de ensinar e de aprender tanto na Educação Básica, quando na universidade.

A Universidade Regional de Blumenau (FURB) foi contemplada com o PIBID a partir de 2010. No EDITAL N 02/2009 - CAPES/DEB foram contempladas cinco licenciaturas: Pedagogia; Artes; Matemática, Química e Ciências Sociais e no EDITAL N $N^{\circ}$ 01/2011, outros três subprojetos envolvendo o Curso de Letras, Educação Física e Matemática. Com a possibilidade de ampliação em 2012, atualmente desenvolve subprojetos também nas áreas: Interdisciplinar; História; Letras-Português, Ciências e Intercultural Indígena. Esta pesquisa analisou as contribuições do PIBID à formação docente nos dizeres dos licenciandos da FURB ingressantes nos anos 2010 e 2011 no Programa. 


\section{PROCEDIMENTOS METODOLÓGICOS}

A pesquisa é de caráter qualitativo, que segundo Bogdan e Biklen (1994), define-se por cinco características básicas: tem o ambiente natural como sua fonte direta de dados e o pesquisador como seu principal instrumento; os dados coletados são predominantemente descritivos; a preocupação com o processo é muito maior do que com o produto; o significado que as pessoas dão às coisas e à sua vida são focos de atenção especial do pesquisador; e a análise dos dados tende a seguir um processo indutivo.

A coleta de dados ocorreu por meio da elaboração de um texto narrativo denominado de memorial. Este recurso é empregado principalmente pelas Ciências Sociais e Humanas que escolheram as "histórias de vida" como objeto de investigação e que segundo Nóvoa (1995, p. 18) "faz reaparecer os sujeitos face às estruturas e aos sistemas, a qualidade face à quantidade, a vivência face ao instituído".

Colaboraram com essa pesquisa os licenciandos bolsistas da FURB que ingressaram no PIBID por meio dos Editais 2010 e 2011 e permaneciam inscritos no primeiro semestre de 2012. A tabela a seguir apresenta a quantidade de licenciandos bolsistas integrantes do PIBID na época, bem como a quantidade de alunos que participaram efetivamente da pesquisa em cada subárea.

TABELA 1 - Relação dos licenciandos participantes da pesquisa

\begin{tabular}{l|l|l}
\hline \multicolumn{1}{c|}{ Subárea } & Alunos bolsistas PIBID & Participantes da pesquisa \\
\hline & & \\
Música & 10 & 06 \\
Pedagogia & 20 & 17 \\
Letras & 14 & 06 \\
Ed. Física & 21 & 16 \\
Matemática (2010) & 20 & 10 \\
Sociologia & 09 & 03 \\
Química & 11 & 05 \\
\hline Total & $\mathbf{1 0 5}$ & $\mathbf{6 3}$ \\
\hline \multicolumn{2}{l}{} \\
\multicolumn{2}{l}{ Fonte: Secretaria do Programa do PIBID Institucional da FURB }
\end{tabular}

Dos 105 licenciandos inscritos no momento da coleta de dados, alguns bolsistas não tinham um ano de experiência no Programa e outros não entregaram ao final o instrumento de coleta de dados, perfazendo, portanto a participação de $60 \%$ de acadêmicos da FURB envolvidos no programa. Os sujeitos pesquisados 
foram convidados a elaborar um breve memorial narrando as contribuições do programa à sua formação inicial. A elaboração dos memoriais foi orientada pelos pesquisadores em encontros presenciais das subáreas. Com os memoriais em mãos, procedemos à análise de conteúdo. Esta técnica de análise de dados, segundo Bardin (1975), compreende procedimentos especiais uma vez que deve ser adequada ao domínio e ao objetivo pretendido, sendo desta forma, reinventada a cada momento, o que não significa improvisação, mas sim, adequação das técnicas no sentido de adaptá-las a cada situação. Assim, não tivemos um caminho rígido a seguir, mas um conjunto de vias possíveis para a revelação do sentido do conteúdo coletado junto aos acadêmicos.

Após a leitura minuciosa dos memoriais organizamos os dados em nove categorias, em ordem decrescente quanto à sua recorrência nos registros analisados: relação entre universidade e Escola Básica; desenvolvimento profissional docente; valorização da profissão docente; desenvolvimento da reflexividade docente; formação do professor pesquisador; qualificação do ensino; formação do professor leitor; uso de novas metodologias de ensino e trabalho colaborativo. A seguir apresentamos a análise de cada categoria separadamente, embora elas estejam intimamente imbricadas. Selecionamos em cada categoria os dizeres dos licenciandos que mais evidenciaram o avanço analisado, relacionandoos com a teoria de suporte da pesquisa.

\section{COMPREENSÃO DOS LICENCIANDOS ACERCA DAS CONTRIBUIÇÕES DO PIBID À SUA FORMAÇÃO}

\section{a) Relação entre universidade e educação básica}

Essa categoria evidencia a contribuição do PIBID promovida pela relação entre Universidade e Escola Básica, composta pelo diálogo entre teoria e prática e pela socialização profissional. Apresentamos a seguir alguns dizeres que proporcionam tal indicador:

"O PIBID possibilitou conhecer a dinâmica escolar, suas limitações e possibilidades [...] A integração e aproximação entre o ensino médio e o 
meio universitário, acredito eu, que seja de grande importância para ambos os lados" (Bolsista $n^{\circ} 3$ de Sociologia);

"O contato com estudantes de Ensino Médio como forma de preparação para a docência permitiu um entendimento mais amplo da clientela que aguarda o docente" (Bolsista n5 de Química);

"O Projeto PIBID contribui na minha formação docente por permitir o contato mais intenso com a realidade escolar da Educação Básica [...]" (Bolsista $n^{\circ} 3$ de Música);

"Podemos também identificar como funciona uma escola, os problemas encontrados e as dificuldades antes de ser professor" (Bolsista $n^{\circ} 3$ de Matemática).

Os recortes apresentados anteriormente fazem menção à experiência profissional, vivência do contexto escolar e compreensões de problemas do cotidiano da profissão docente. Freitas (2002, p. 156) define a socialização profissional como o contato do licenciando com o contexto escolar e que "constituise na aprendizagem dos valores, crenças e formas de concepção do mundo, próprios de uma determinada cultura ocupacional". A socialização profissional é caracterizada pela inserção do futuro docente ao seu campo de atuação, envolvendo assim um processo de aculturação profissional.

Nesse processo, o novo docente chega à escola com seus ideais e entra em choque com uma dicotomia entre teoria e prática, cuja distinção ainda é recorrente em algumas realidades tanto da Educação Básica como na Educação Superior. Conforme destacou um licenciando "A oportunidade de vivenciar um meio escolar [...] nos mostra o que na prática realmente funciona e o que não passa de um belo discurso" (Bolsista $n^{\circ} 1$ de Matemática). Tal afirmação caracteriza o processo de socialização profissional, no qual, ideais construídos na academia (belo discurso) são desconstruídos ao entrarem em contato com a realidade escolar (o que funciona na prática). Flores (2010) sugere que a socialização profissional antecipatória, ou seja, durante a graduação, ameniza o choque causado pela socialização profissional ocorrida na escola no momento de incursão do novo docente, reforçando crenças e teorias implícitas.

Os dados analisados nesta categoria evidenciam que o programa tem contribuído para a formação inicial de professores mais contextualizada à realidade educacional, com mais conhecimento prático e teórico acerca da profissão docente, proporcionando uma formação mais ampliada aos licenciandos que dele participam, 
assim como, destaca-se a ampliação de tempos e espaços da formação dos bolsistas envolvidos.

\title{
b) Desenvolvimento profissional docente
}

As atuais dinâmicas sociais fomentam debates educacionais acerca da qualificação da formação docente e da prática pedagógica. Segundo Formosinho (2009, p. 226) "o desenvolvimento profissional é um processo contínuo de melhoria das práticas docentes", ocorre na interação com o contexto e tem por objetivo a melhoria da realidade escolar. Esse tipo de desenvolvimento profissional é evidenciado pelos acadêmicos bolsistas de diversas subáreas:

\begin{abstract}
"A inserção no campo de atuação faz com que possamos nos preparar melhor para vencer os desafios impostos a nós, em nossa jornada profissional, e por estarmos dentro da faculdade, podemos confrontar a teoria com a prática, e assim melhorando a nossa postura e forma de atuar nas escolas" (Bolsista $n^{\circ} 4$ de Educação Física);

"Não posso dizer que hoje, após essa experiência, me sinto preparada para encarar todos os desafios que aparecerão no decorrer de minha carreira docente, mas posso afirmar que aprendi o caminho de achar respostas para a resolução dos problemas que surgirão" (Bolsista n³ de Pedagogia).
\end{abstract}

O desenvolvimento profissional destacado pelos acadêmicos relaciona-se com a perspectiva de desenvolvimento profissional autônomo de Formosinho (2009), no qual os docentes buscam no próprio contexto educacional o norte para desenvolver a prática docente.

Conforme Garcia (1999), a formação docente integra o desenvolvimento profissional, mas não é o único componente. Destaca que a formação adota diferentes aspectos de acordo com o sentido que se atribui ao objeto da formação, ou da concepção que se tem pelo sujeito. Para o autor, o desenvolvimento profissional é como um processo de aprendizagem de algo por alguém no contexto que está inserido. Os memoriais mencionam a ampliação da formação dos acadêmicos bolsistas pela construção de conhecimentos de dimensões que a matriz curricular do curso de licenciatura não é capaz de suprir: 
"Através do PIBID tive a oportunidade de participar de minicursos, palestras e formações com os professores que o currículo do curso em si não abordava" (Bolsista $n^{\circ} 7$ de Pedagogia);

"Antes de atuarmos de fato na escola, o processo de preparo para essa atuação é que também faz todo o diferencial” (Bolsista $n^{\circ 1}$ de Música).

Entendemos que a formação inicial não dá conta, sozinha, de formar um profissional preparado para exercer a complexa função docente, entretanto, ela tem um papel fundamental na inserção do profissional no campo de trabalho. Entendemos que a experiência adquirida pelos licenciandos bolsistas participantes do PIBID, certamente, contribui para amenizar o choque com a realidade do professor no inicio de sua profissão docente.

\section{c) Valorização da profissão docente}

Os memoriais analisados apresentam a complexidade da profissão docente na contemporaneidade. Das vinte descrições selecionadas dos memoriais que fazem menção a essa categoria, apenas quatro apontam aspectos positivos da docência. As demais atribuem valores negativos à docência como dificuldades do cotidiano, falta de prestígio social do profissional e excesso de funções do professor. Esses são dilemas capazes de gerar incertezas às funções reais do professor no cotidiano escolar (ALARCÃO, 2001). As políticas públicas resolvem os problemas atribuindo novas funções à escola que as adota sem contestar (NÓVOA, 2007; GATTI, 2009). A sobrecarga de funções estabelece uma meta impossível de ser atingida pelo professorado.

O professor, diante das variadas funções que a escola pública assume, tem de responder a exigências que estão além de sua formação. Muitas vezes esses profissionais são obrigados a desempenhar funções de agente público, assistente social, enfermeiro, psicólogo, entre outras. Tais exigências contribuem para um sentimento de desprofissionalização, de perda de identidade profissional, da constatação de que ensinar às vezes não é o mais importante (OLIVEIRA, 2004, p.1132).

Segundo o licenciando bolsista $\mathrm{n}^{\circ} 9$ de Educação Física, "o professor ainda acaba tendo de interferir e ajudar em situações de relacionamento entre as crianças", fazendo o papel de conciliador e psicólogo. Dialogando com os autores 
mencionados, esse acúmulo de funções tem grande poder desmotivador e acaba por relegar a construção de conhecimentos ao segundo plano de prioridades.

Segundo Gatti (1991), a carreira docente tem se mostrado cada vez menos atraente, seja pela formação, pelas condições de exercício ou salariais. Aproximadamente $40 \%$ dos licenciandos não pretendem exercer a profissão, e grande parte daqueles interessados em atuar estão apreensivos quanto à instabilidade social e financeira da carreira. Esses dados apresentados pela autora são também perceptíveis nos memoriais dos acadêmicos bolsistas analisados:

"[...] percebo as qualidades e pontos negativos dessa área. O Programa contribui para minha escolha de trabalhar ou não em escola" (Bolsista $n^{\circ} 2$ de Educação Física);

"Querer ou não ser professor, o projeto nos ajuda a decidir" (Bolsista n¹4 de Educação Física);

"[...] apesar da dificuldade que os professores encontram para trabalhar, em termos de procedimento comportamental dos alunos e a falta de incentivo do poder público, com baixo salário e poucos recursos para trabalhar, sintome motivado para lecionar a disciplina" (Bolsista n³ de Química);

"É como uma ponte que nos liga, exatamente ao que buscamos e estamos nos preparando para viver" (Bolsista $n^{\circ} 2$ de Letras);

"Poderão desde cedo conhecer os encargos da profissão professor e dessa forma, perceber se de fato é isto que esperam para seu futuro" (Bolsista $n^{\circ} 3$ de Matemática).

No último decênio do século passado já fora apontada a desvalorização da profissão docente, incluindo aqui a falta de prestígio social, baixa remuneração e condições inadequadas de atuação, gerando escassez de profissionais para a educação. "Salários aviltantes, desvalorização profissional, imagem social ambígua dos professores, baixa autoestima e descontinuidade de políticas são fatores de perturbação e desarticulação nos sistemas de ensino, sem nenhuma dúvida" (GATTI, 1991, p.64).

O professor é considerado figura central no processo de ensino e seu papel é imprescindível para o sucesso no processo de significação de novos conhecimentos. A constituição de uma escola reflexiva vem a suprir algumas das necessidades, mas ela não é capaz, sozinha, de proporcionar uma carreira mais atraente aos professores. Eis o dilema: Como formar professores reflexivos quando é perceptível "o cansaço e o desânimo manifestados por tantos professores que, sentem-se 
solitários, desapoiados pelos dirigentes, pelas comunidades e pelos governos?" (ALARCÃO, 2001, p.16).

\section{d) Desenvolvimento da reflexividade docente}

Compreendemos aqui a reflexividade docente como o processo de refletir da/na/para a própria prática à luz da teoria, a fim de aprimorar a sua docência. Configuram essa categoria os acadêmicos bolsistas que mencionam o processo da reflexão em seus memoriais:

"O programa está proporcionando uma experiência valiosíssima. Os licenciando bolsistas passam a analisar criticamente os teóricos que permeiam a sua área de atuação, passando a adaptar suas teorias ao próprio contexto e através desta prática crítico-reflexiva, transformar sua prática docente" (Bolsista n4 de Música).

Na perspectiva desse acadêmico fica clara a reflexividade como o processo de mediação de teoria e prática para a ressignificação da docência. Ainda que não mencionem a teoria, outros acadêmicos também apresentam resultados da reflexão sobre a prática docente:

"[...] faz o acadêmico refletir sobre suas práticas diferenciadas, com o intuito de detectar as dificuldades dos alunos para posteriormente planejar sua ação" (Bolsista n¹ de Letras);

\footnotetext{
"Desenvolver a experiência de docente neste programa permitiu-me refletir sobre toda a problemática da educação, o papel da escola, dos professores e alunos" (Bolsista $n^{\circ} 5$ de Pedagogia);

"[...] cada vez mais estou entendendo que ser professor não é simplesmente chegar numa quadra e dar uma bola para as crianças e deixá-las à vontade. O professor antes de tudo deve planejar sua aula e estar preparado para pequenas e grandes situações que modifiquem seu planejamento" (Bolsista n॰9 de Educação Física).
}

No momento em que a prática é tomada como objeto de reflexão, acontece a reflexão sobre a ação, que se refere a uma ação mais sistemática que permite análise e a reformulação da prática. É o olhar introspectivo e proativo sobre a ação de forma que seja possível analisar o que aconteceu e qual foi o significado que foi atribuído aos acontecimentos (SCHON, 1987). Por meio dos memoriais constatamos 
desdobramentos da reflexividade apontando para a mudança da percepção dos licenciandos bolsistas sobre a escola e a profissão docente.

\section{e) Formação do professor pesquisador}

O PIBID tem apresentado contribuições à formação de professores pesquisadores, tema esse que é discutido no Brasil desde a década de 1980. A FURB, compactuando com as Diretrizes para a formação Inicial de Professores da Educação Básica em Cursos de Nível Superior, adotou essa proposta de fomento à pesquisa a fim de formar um professor que reflita a sua prática profissional por meio da atitude investigativa (RAUSCH, 2010a). Mesmo assim, ainda é tímido o incentivo de produção científica na graduação, conforme evidenciado pelo licenciando bolsista:

"Defino o PIBID como proporcionador de pesquisa, novos conhecimentos acadêmicos, vivências que aprendemos como devemos lidar, vivências das quais teoricamente sabemos que vamos enfrentar, mas que o curso não supre" (Bolsista $n^{\circ} 6$ de Pedagogia).

Para Lüdke (2001), o currículo da graduação não contempla a pesquisa, ou parcamente o faz. Os professores formados não são capazes de tal iniciativa sozinhos, visto que a figura de um orientador é de suma importância no processo, como destaca Rausch (2010b). Professores sem o contato com a pesquisa, permanecem sem praticá-la e atribuem essa tarefa a mestres e doutores.

Adotamos nessa pesquisa o conceito de professor pesquisador como aquele profissional docente que busca através da investigação sistematizada o entendimento e a transformação do seu cotidiano, seguindo processos básicos da pesquisa acadêmica para gerar novos conhecimentos (RAUSCH, 2011). Esse processo investigativo é apresentado nos memoriais de todas as subáreas do PIBID FURB. Destacamos alguns relatos:

\footnotetext{
"Através da pesquisa que eu e minha equipe estamos desenvolvendo vamos levantar quais as necessidades do aluno e como vamos trabalhar no futuro para vencê-las dentro da sala de aula" (Bolsista $n^{\circ} 6$ de Letras);

"O processo de escrita de um artigo a partir da experiência vivenciada, tendo como base nosso referencial teórico, também foi uma construção, que
} 
mostrou a importância de registrar nosso trabalho, escrever sobre ele, refletir sobre o que estamos fazendo, e como estamos nos construindo professores" (Bolsista $n^{\circ} 17$ de Pedagogia).

Nóvoa (2011) aponta quão falha é a capacidade dos professores de tornar público aquilo que Ihes compete, suas atividades, pesquisas e resultados. Dessa forma, acaba por isolar-se em seus ideais que nada contribuem para o reconhecimento e a valorização da profissão docente. A atitude de socialização dos trabalhos, seja em eventos nacionais, estaduais ou em seminários internos promovidos pelo PIBID, é capaz de exercitar tal competência e desmistificar este processo, conforme descrevem os acadêmicos bolsistas:

\footnotetext{
"Recentemente nosso grupo enviou um artigo e um pôster para a ABEM (Associação Brasileira de Educação Musical) que foram aceitos. Com certeza o PIBID tem feito diferença em minha formação" (Bolsista $n^{\circ 1}$ de Música);

"O programa permitiu a produção científica que trouxe a socialização de atividades e a troca de ideias com outras pessoas, proporcionando um crescimento pessoal e integração com o meio acadêmico" (Bolsista $n^{\circ} 5$ de Química);

"Estamos trabalhando na criação de banners e amostras para encontros que são proporcionados com bolsistas PIBID" (Bolsista n5 de Matemática);

"Os resultados obtidos com este trabalho renderam um resumo enviado para o XVI Encontro Nacional de Educação Química, a ser realizado em Salvador, em julho de 2012." (Bolsista $n^{\circ 1}$ de Química);

"Também trabalhamos na construção de artigos a partir dos resultados das análises" (Bolsista $n^{\circ} 1$ de Letras).
}

Têm-se aqui iniciativas de produção de conhecimento por futuros professores que pesquisam as próprias práticas, fato esse que tende à qualificação do ensino a médio e longo prazo e valorização da profissão docente, cujo ator entra em cena e reivindica seu lugar na sociedade.

\section{f) Qualificação do ensino}

Para alguns acadêmicos bolsistas a qualificação do ensino propiciada pelo PIBID está relacionada ao rompimento do tradicionalismo pedagógico ainda vigente nas redes públicas de ensino, para a adesão a uma cultura educacional que 
considere o contexto sociocultural a fim de proporcionar conhecimentos mais significativos para todos os envolvidos:

\begin{abstract}
"A educação tem que ser significativa para os alunos, para a construção do conhecimento, partir da realidade dele, no seu meio social para após buscar transformá-la quando necessário, obtendo uma reflexão crítica comprometida com a ação pedagógica" (Bolsista n² de Pedagogia);

"O projeto permite quebrar com a lógica educacional vigente. [...] propicia uma visão ampla da importância de desenvolver um plano de ensino adequado ao contexto dos alunos e a importância de desenvolver aulas dinâmicas que acompanham o desenvolvimento científico tecnológico" (Bolsista $n^{\circ} 2$ de Ciências Sociais).
\end{abstract}

Percebemos que os acadêmicos consideram o programa um processo que permite rompimentos com a educação bancária tão criticada por Freire (1987), mas ainda tão presente no sistema educacional brasileiro, e avança para a perspectiva dialógica e emancipadora de educação, desenvolvendo um novo perfil de professor. Nesta direção, Tardif (2007, p. 230) aponta uma nova perspectiva de professor para a atualidade:

\begin{abstract}
Um professor de profissão não é somente alguém que aplica conhecimentos produzidos por outros, não é somente um agente determinado por mecanismos sociais: é um ator no sentido forte do termo, isto é, um sujeito que assume sua prática a partir dos significados que ele mesmo lhe dá, um sujeito que possui conhecimentos e um saber-fazer provenientes de sua própria atividade e a partir dos quais ele a estrutura e a orienta.
\end{abstract}

As propostas interdisciplinares tão discutidas nos processos de ensinar e de aprender também foram mencionadas pelos licenciandos:

\begin{abstract}
"Buscamos sempre apresentar métodos inovadores muitas vezes relacionados com as demais disciplinas escolares, sempre com o intuito de uma melhoria no processo de ensinar e aprender" (Bolsista $n^{\circ} 5$ de Matemática).

"Todas as pessoas envolvidas neste projeto, sem exceção, são beneficiadas intelectualmente" (Bolsista $n^{\circ} 1$ de Educação Física).
\end{abstract}

Os apontamentos mais comuns foram relacionados à aprendizagem pela ludicidade, através de jogos e materiais didáticos mais dinâmicos, das propostas educacionais inovadoras que dialogam com o contexto no qual se inserem, bem 
como uma nova forma de pensar e compreender os processos de ensinar e de aprender, vislumbrando, com isso, a possibilidade de uma mudança do panorama educacional atual.

\section{g) Formação do professor leitor}

Torna-se cada vez mais difícil não ser leitor na sociedade grafocêntrica em que vivemos (TARDELLI, 1997). O Índice de Analfabetismo Funcional (INAF) levantado pela Instituição Paulo Montenegro em 2012, aponta que atualmente 73\% da população brasileira entre 15 e 64 anos é alfabetizada funcional (Básica e Plena) e $27 \%$ é analfabeta funcional (Analfabeto e Rudimentar). Os dados apontam ainda a constante redução do analfabetismo funcional ocorrido pelo aumento da renda familiar, porém, a alfabetização plena que possibilita a compreensão de textos mais longos e complexos não mudou ao longo da década. Assim, ainda que consigamos todos conviver nessa sociedade grafocêntrica, o nível de instrução é relativamente baixo devido à falta do hábito de leitura de livros e textos e da curta trajetória da literatura no Brasil (TARDELLI, 1997).

O PIBID FURB fomenta a atitude de leitura nos licenciandos bolsistas, por entender que antes de ensinar a ler, é fundamental que o professor seja leitor e se insira continuamente em processos e eventos de letramento. Os memoriais de licenciandos de diferentes subáreas apontam o aumento da leitura de textos acadêmicos e científicos que norteiam a prática docente:

\footnotetext{
"Comecei a ler mais depois de entrar no PIBID, e isso é ótimo. Tento buscar na literatura solução de alguns problemas comportamentais" (Bolsista $n^{\circ} 6$ de Educação Física);

"São recomendadas leituras de diversos autores da nossa área, o que nos dá suporte teórico" (Bolsista n¹ de Música);

"Nos primeiros meses tivemos muita formação teórica, estudamos sobre contos de fada e sua estrutura, através de Scliar Cabral" (Bolsista $n^{\circ} 3$ de Letras);

"Ao entrar em contato com os escritos de Magda Soares e discutir esses conceitos, ler, reler, discutir em grupo, registrar, foram ampliando meu entendimento sobre esses conceitos" (Bolsista $n^{\circ 17}$ de Pedagogia).
} 
Temos nesses relatos o claro desenvolvimento da atitude de leitura que, por sua vez, possibilita o desenvolvimento de futuros docentes letrados, que fazem da leitura cotidiana parte do seu capital intelectual e cultural, o que the serve de auxilio para o aprimoramento constante da prática docente, qualificando os processos de ensinar e de aprender.

\section{h) Novas metodologias de ensino}

Os dizeres dos bolsistas pibidianos acerca de novas metodologias de ensino apresentam a necessidade de rompimento do tradicionalismo pedagógico, produção de materiais ludo-pedagógicos e inserção de novos saberes curriculares, disciplinares e pedagógicos na educação básica.

O rompimento do tradicionalismo pedagógico aponta uma relação dialógica entre professor e aluno, assim como o questionamento crítico sobre o conteúdo e sua relação com o cotidiano, buscando uma perspectiva educacional interdisciplinar e construtivista:

\footnotetext{
"As bolsistas buscam superar os problemas apresentados em sala de aula de uma forma interdisciplinar, motivando os alunos a novas descobertas e a novos meios de aprendizagem ainda não conhecidos" (Bolsista $n^{\circ} 8$ de Matemática);

"Podemos ver que a busca do saber torna-se importante e prazerosa quando a criança aprende brincando. É possível, através de jogos e brincadeiras, formar indivíduos com autonomia, motivados para muitos interesses e capazes de aprender rapidamente" (Bolsista $n^{\circ} 3$ de Pedagogia);

"Conhecer a dinâmica escolar, suas limitações e possibilidades. Discuti-las junto aos colegas do projeto e do professor orientador e pensarmos, em conjunto, em práticas transformadoras das condições pré-estabelecidas pela atual dinâmica de reprodução social foi muito significativo" (Bolsista $n^{\circ} 3$ de Ciências Sociais).
}

A produção de materiais ludo-pedagógicos que compõe o planejamento das propostas pedagógicas das subáreas de Química e Matemática promoveu a inclusão social conforme descrito no memorial dos licenciandos: 
vezes, mais complexo ou de melhor assimilação de um conteúdo por vezes já conhecido ou não, é uma experiência única" (Bolsista nº5 de Matemática);

"Está em andamento um trabalho que visa à inclusão de deficientes visuais no Ensino de Química. O projeto trata da construção de uma tabela periódica em braile, para que possa ser utilizada por deficientes visuais na Educação Básica" (Bolsista n¹ de Química).

A subárea música, por sua vez, enfrenta um panorama diferenciado das demais subáreas por ainda não estar presente como disciplina no currículo escolar regular. Contemplada pela LDB 11.769/08 que visa à obrigatoriedade do ensino de música na escola, a música voltou a ser um saber disciplinar abordado na escola, porém, muito pouco ainda se fez para tal. O PIBID possibilita a entrada da formação musical nas escolas envolvidas sob a regência de licenciandos em música que desde o princípio desenvolvem projetos que visam à experimentação de metodologias de ensino de música para o contexto escolar:

\begin{abstract}
"Em música, principalmente, atuamos de forma transformadora a fim de adotar as tendências da educação musical, amparada pela Lei 11.769, sancionada em 2008 que visa à obrigatoriedade da música nas escolas básicas brasileiras, mas que ainda não está efetivamente em prática nas escolas por uma série de fatores, dentre eles, a falta de professores com formação específica, falta de planejamento, e falta de orientação de toda a comunidade escolar [...]" (Bolsista ${ }^{\circ} 4$ de Música).
\end{abstract}

Mudanças significativas no processo de ensinar e aprender têm sido exploradas pelos licenciando bolsistas e os resultados já começam a ser evidenciados com ênfase aqui especialmente ao construtivismo e à dialogicidade.

\title{
i) Trabalho colaborativo
}

O trabalho colaborativo é constituído por pessoas que compartilham decisões, ou ações conjuntas e são responsáveis pela eficácia e qualidade de suas ações. Os bolsistas destacaram que este processo ocorre no PIBID:

"Foi com a ajuda das coordenadoras e supervisoras que passei a refletir melhor e de outra forma sobre os processos de ensino e de aprendizagem" (Bolsista $n^{\circ} 3$ de Pedagogia);

"O final do ano também reservou bons momentos de construção coletiva no I Seminário PIBID FURB, em que pudemos socializar com as demais 
licenciaturas o trabalho desenvolvido na Pedagogia, e em geral como o PIBID vem acontecendo na FURB." (Bolsista $n^{\circ} 17$ de Pedagogia);

"Desenvolvendo atividades e planejamentos com a professora de língua portuguesa daquela escola, com o objetivo de fazer com que o aluno desperte o gosto pela leitura e pela escrita" (Bolsista $n^{\circ} 4$ de Letras).

Os acadêmicos bolsistas apontam o trabalho colaborativo como um promotor de novos conhecimentos, pela troca de experiências entre os docentes experientes, e pela construção de novas metodologias de ensino aprendizagem. Diante das inúmeras dificuldades encontradas na Educação Básica, Nóvoa (2011) destaca a importância do trabalho colaborativo como um dos meios que podem proporcionar ao docente oportunidades de aprendizagens e de trabalho com qualidade.

É na troca de experiências que os profissionais começam a reconhecer o que sabem e refletem sobre sua prática, de modo a ressignificar a sua maneira de pensar e agir na docência, proporcionando novas possibilidades de estarem resolvendo seus dilemas. O trabalho colaborativo proporciona a solidariedade, a troca de experiências e de valores, saberes que não podem ser desenvolvidos individualmente.

\section{CONSIDERAÇÕES FINAIS}

O PIBID tem apresentado desdobramentos que apontam a possibilidade da qualificação do ensino a médio e longo prazo, formando docentes mais cientes do contexto em que atuarão, produtores de conhecimentos, com posturas investigativas e reflexivas acerca da própria prática docente. Alguns relatos dos licenciandos, participantes da pesquisa, salientaram o desenvolvimento de profissionais colaboradores entre si e autônomos. Colaboradores por trabalharem em conjunto com professores experientes, alunos e pais da Educação Básica e a própria universidade, e autônomos por desenvolverem em sua formação e atuação processos próprios de docência.

As principais contribuições do PIBID à formação inicial de professores apresentados pelos licenciandos bolsistas foram: relação entre universidade e escola básica, desenvolvida principalmente por meio da socialização profissional antecipatória e pela relação entre teoria e prática; desenvolvimento profissional 
docente, destacando o aprimoramento da prática docente no cotidiano escolar; valorização da profissão docente, pela adaptação e conscientização das condições de trabalho profissional; desenvolvimento da reflexividade docente por meio da reflexão dalparalsobrelna prática docente; formação do professor pesquisador a partir da produção e socialização de novos conhecimentos sistematizados sobre a prática docente; qualificação do ensino pelo desenvolvimento de conhecimentos didático-pedagógicos; formação do professor leitor no desenvolvimento de atitudes de leitura que contribuíram para o letramento dos licenciando bolsistas; novas metodologias de ensino e aprendizagem a partir de metodologias ativas e o trabalho colaborativo por meio da integração de profissionais de diferentes contextos educativos.

O desenvolvimento de profissionais docentes colaboradores entre si e autônomos são aspectos fundamentais à qualificação do ensino no país. Entretanto, além da formação inicial de professores, há de se pensar também no acompanhamento dos professores iniciantes, em sua formação continuada (de modo a considerar a formação inicial), seus planos de carreira, bem como na infraestrutura das escolas de Educação Básica no país.

Outro aspecto que nos preocupa é que nem todos os licenciandos têm condições de participar do PIBID. Neste sentido, os demais processos formativos constituintes da formação inicial dos professores devem ser atenciosamente analisados, avaliados e ressignificados.

Salientamos, por fim, que essa pesquisa analisou as contribuições do PIBID à formação inicial de licenciandos bolsistas de diferentes subáreas. Mas ao considerar a autonomia das propostas e as idiossincrasias de cada área do conhecimento, recomendamos o aprofundamento desse estudo analisando as contribuições do programa em cada subárea especificamente, considerando aspectos como organização, gestão, fundamentação e metodologia, a fim de obter resultados sobre os desdobramentos dos diferentes sistemas organizacionais das subáreas para a formação inicial dos estudantes. Outra recomendação é ouvir os dizeres de outros segmentos participantes, como os supervisores, coordenadores de área e coordenadores institucionais e de gestão analisando também as suas compreensões acerca das contribuições do PIBID à formação inicial dos professores. 


\section{RITA BUZZI RAUSCH}

Doutora em Educação pela UNICAMP. Professora pesquisadora na Universidade Regional de Blumenau (FURB) no curso de Pedagogia e no Mestrado em Educação (PPGE/ME/FURB). Coordena o Programa de Iniciação à Docência (PIBID/CAPES) na subárea Pedagogia.

\section{MATHEUS JURGEN FRANTZ}

Graduando em Música pela Universidade Regional de Blumenau (FURB). Bolsista do Programa de Incentivo à Pesquisa (PIPe/FURB) e do Programa de Iniciação à Docência (PIBID/CAPES).

\section{REFERÊNCIAS}

ALARCÃO, I. Escola reflexiva e nova racionalidade. Porto Alegre: ARTMED Editora, 2001.

BARDIN L. Análise de conteúdo. Lisboa Edições 70, 1975.

BRASIL. Coordenação de Aperfeiçoamento de Pessoal de Nível Superior. http://www.capes.gov.br/educacao-basica/capespibid. Acesso em: 11/01/2012.

BRASIL. Ministério de Educação e Cultura. Lei N 11.769 de 10 de agosto de 2008.

BRASIL. Coordenação de Aperfeiçoamento de Pessoal de Nível Superior. Edital $\mathbf{n}^{\circ}$ 2 do Programa Institucional de Bolsa de Iniciação a Docência de 2009.

BRASIL. Coordenação de Aperfeiçoamento de Pessoal de Nível Superior. Edital $\mathbf{n}^{\circ}$ 1 do Programa Institucional de Bolsa de Iniciação a Docência de 2011.

BOGDAN, R.; BIKLEN, S. Investigação qualitativa em educação: uma introdução à teoria e aos métodos. Porto: Porto Editora, 1994.

FLORES, M. A. Algumas Reflexões em torno da formação inicial de professores. Educação. Porto Alegre, v.33, n.3, p. 182 - 188, set./dez. 2010. Disponível em: <http://redalyc.uaemex.mx/src/inicio/ArtPdfRed.jsp?iCve=84816931003>. Acessado em: 03 Mai. 2012.

FONTANA, R. A. C. e CRUZ, M. N. da. Psicologia e trabalho pedagógico. São Paulo: Atual, 1997.

FORMOSINHO, J. O (org.). Formação de professores: Aprendizagem profissional e acção docente. Portugal, Porto Editora, 2009.

FREIRE, P. Pedagogia do Oprimido. $11^{a}$ Edição, Rio de Janeiro. Paz e Terra, 1987. 
FREITAS, M. N. V. Organização Escolar e Socialização Profissional de Professores Iniciantes. Cadernos de Pesquisa, n. 115, março/ 2002. Disponível em: <http://www.scielo.br/pdf/cp/n115/a06n115.pdf>. Acessado em: 19 Mai. 2012

GARCIA, C. M. Formação de professores para uma mudança educativa. Trad. Isabel Narciso. Porto, Portugal: Porto Editora, 1999.

GATTI, B. A.; BARRETO, E. S. S. Professores do Brasil: impasses e desafios. Brasília: UNESCO. 2009.

GATTI, B. A. Formação de professores: Condições e problemas atuais - Fundação Carlos Chagas. Revista Brasileira de Formação de Professores - Vol. 1, $n^{\circ} 1, p$. 90 - 102, Maio/2009.

GATTI, B. A. Formação de professores e carreira - Problemas e movimentos de renovação. Campinas, SP: Autores Associados, 1991. (Coleção Formação de Professores).

LÜDKE, M. A complexa relação entre o professor e a pesquisa. Campinas, SP. Papirus, 2001.

NÓVOA, A. O Regresso dos Professores. Pinhais PR. Editora Melo, 2011.

NÓVOA, A. Desafios do Trabalho do Professor no Mundo Contemporâneo. Palestra ao SINPRO. SP. $2007 . \quad$ Disponível em http://www.sinprosp.org.br/arquivos/novoa/livreto novoa.pdf>. Acessado em: $20 \mathrm{Jul}$. 2012.

NÓVOA, A. Vidas de professores. 2. ed. Porto: Porto Editora Ltda, 1995.

OLIVEIRA, D. A. - A reestruturação do trabalho docente: precarização e flexibilização. Educação e Sociedade. Campinas, vol. 25, n. 89, p. 1127-1144, Set./Dez. 2004

RAUSCH, R. B. Concepções e experiências em pesquisa de licenciandos em conclusão de cursos. 33ª Reunião Anual do ENDIPE. 2010a.

Reflexividade e Pesquisa: Articulação necessária na formação inicial de professores. Blumenau. Edifurb, 2010b.

Pesquisa em educação: pressupostos epistemológicos e dinâmicas de investigação. Blumenau, SC. Edifurb, 2011.

$\mathrm{SCHON}, \mathrm{D}$. A. Educando o profissional reflexivo. Porto Alegre: Artes Médicas, 1987.

TARDELLI G. M. P. História de leitura: A formação do professor leitor. Campinas, SP. Unicamp, 1997. Disponível em http://www.bibliotecadigital.unicamp.br/document/?code=vtls000288045\&opt=4.

Acessado em: 16 de out. de 2012. 
ATOS DE PESQUISA EM EDUCAÇÃO - PPGE/ME

ISSN 1809-0354 v. 8, n. 2, p.620-641, mai./ago. 2013

DOI http://dx.doi.org/10.7867/1809-0354.2013v8n2p620-641

TARDIF, M. Saberes docentes e formação profissional. $8^{a}$ edição. Petrópolis, RJ. Vozes, 2007. 